\title{
Teocentrismo, Antropocentrismo y Contabilidad: de la Edad Media al Renacimiento
}

\section{Susana Villaluenga de Gracia $^{a}$, Inmaculada Llibrer-Escrig ${ }^{\mathrm{b}}$, Fernando-Gabriel Gutiérrez- Hidalgo ${ }^{c}$}

a) Facultad de Ciencias Jurídicas y Sociales de Toledo, Universidad de Castilla-La Mancha, Toledo, SPAIN.

b) Facultad de Ciencias Económicas y Empresariales, Universidad Católica de Valencia, Valencia, SPAIN.

c) Facultad de Ciencias Empresariales, Universidad Pablo de Olavide, Sevilla, SPAIN.

${ }^{a}$ Corresponding author.

E-mail address: susana.villaluenga@uclm.es

\section{A R T I C L E I N F O}

\section{Article history:}

Received 28 March 2020

Accepted 28 July 2020

Available online 1 January 2022

\section{Códigos JEL:}

M41

M42

M49

Palabras clave:

Partida doble

Cargo-descargo

Método contable

Teocentrismo-Antropocentrismo

Religión

Edad Media-Renacimiento

\section{JEL classification: \\ M41}

M42

M49

Keywords:

Double entry

Cargo-discharge

Accounting method

Theocentrism-Anthropocentrism

Religion

Middle Ages-Renaissance

\section{R E S U M E N}

El cambio del método contable de la partida simple a la doble en el siglo XV se ha intentado explicar por la influencia de diferentes factores como la aparición del capitalismo o por el contacto de Italia con otros pueblos. Sin embargo, ninguno de ellos aisladamente, lo ha podido hacer de forma satisfactoria. Por lo tanto, utilizando una metodología cualitativa, este trabajo intenta arrojar luz indagando cómo este cambio contable se pudo deber a un cambio en la percepción filosófica y religiosa del mundo, al pasarse de la Edad Media al Renacimiento. Se verá cómo los métodos del cargo y descargo y de la partida doble responden a las formas de pensamiento imperantes en el que se desarrollaron. En consecuencia, que partida simple se puede asociar a un pensamiento Teocéntrico, propio de la Edad Media, y que la partida doble se puede relacionar con el Antropocéntrico característico del Renacimiento.

C2022 ASEPUC. Published by EDITUM - Universidad de Murcia. This is an open access article under the CC BY-NC-ND license (http://creativecommons.org/licenses/by-nc-nd/4.0/).

Theocentrism, Anthropocentrism and Accounting: from the Middle Ages to the Renaissance

A B S T R A C T

The change in the accounting method from single entry to double entry in the 15th century has been tried to explain by the influence of some different issues such as the appearance of capitalism or by the contact of Italy with other peoples. However, none of them has been able to do so satisfactorily. That is why this work, tries to show how this accounting change could be pushed by a paradigm shift: the philosophical and religious perception of the world and its passed from the Middle Ages to the Renaissance. It will be seen using a qualitative methodology which helps to know how the methods of charge and discharge and double entry respond to the prevailing ways of thinking in which they developed. The first one, can be associated with a Theocentric thought, typical of the Middle Ages, and the second one, double entry bookkeeping, philosophical viewpoint that are the are the most important entity in the world, which is characteristic of the Renaissance.

(C)2022 ASEPUC. Publicado por EDITUM - Universidad de Murcia. Este es un artículo Open Access bajo la licencia CC BY-NC-ND (http://creativecommons.org/licenses/by-nc-nd/4.0/). 


\section{Introducción}

A pesar de que, desde la década de los ochenta, numerosos trabajos han mostrado que la contabilidad ha condicionado su entorno y viceversa (Hopwood, 1987 y Hopwood \& Miller, 1994), la influencia de la religión en la contabilidad ha sido poco estudiada (Carmona \& Ezzamel, 2006). Así, como las corrientes de pensamiento y las manifestaciones artísticas están impregnadas de la forma de razonar de sus hacedores en un tiempo histórico concreto, en este trabajo se indagará cómo la contabilidad también lo está. Por esta razón la investigación histórica requiere de un análisis contextual de los factores sociales, económicos y políticos del periodo a investigar (Previts \& Bricker, 1994, p. 627) y que los cambios en las técnicas contables están unidos a cambios sociales (Miller \& O'Leary, 1987 y 1989; Miller, 1991; y Bhimani, 1994). La contabilidad puede estudiarse desde el punto de vista técnico, por su capacidad de resolver problemas de registro y comunicación, pero también, desde una perspectiva social, por su papel como creadora de estructuras de pensamiento en sus entornos (Carmona et al., 2004).

Al considerar un periodo histórico de grandes cambios como el paso de la Edad Media a la Moderna, dos métodos contables destacan del resto: el cargo y descargo; y la partida doble. El paso de uno a otro se ha intentado explicar por la influencia de diferentes factores, pero hasta ahora ninguno de forma aislada lo ha podido hacer satisfactoriamente (Oldroyd \& Dobie, 2009, p. 108). Ambos métodos han sido considerados exponentes de la evolución económica de los negocios, pero también de los cambios sociales, culturales e ideológicos acontecidos en este periodo (Hoskin \& Macve, 1986), donde se pasa de una idea del mundo estática y pasiva, propia de la Edad Media, a una dinámica y activa característica del Renacimiento y que diversos autores han vinculado al incipiente capitalismo (Bryer, 2000a, 2000b, 2006; Toms, 2010).

De acuerdo con lo anterior, cabe preguntarse si el cargodescargo y la partida doble pueden ser asociados a un pensamiento característico de dos épocas. El primero a un Teocentrismo, propio de la Edad Media; y el segundo a un Antropocentrismo, propio del Renacimiento. Estas formas de pensamiento coexistieron en Europa en la transición de la Edad Media a la Edad Moderna y dieron lugar a dos formas de razonar, acomodando cada una la percepción de la realidad contabilizada a unos arquetipos ${ }^{1}$ de pensamiento, que tienen su reflejo en los dos métodos contables analizados: la partida simple y la doble. Para estudiar esta cuestión se parte de cuatro premisas: i) la contabilidad registra la realidad económica; ii) cada método contable es un resultado de la actividad humana que pretende registrarse; iii) una misma realidad puede ser registrada de forma diferente según el método seleccionado; y iv) la contabilidad es un lenguaje a través del cual se obtiene una imagen de dicha realidad vinculada a estructuras mentales (López Pérez \& Rodríguez Ariza, 2002).

En este contexto, para responder a la cuestión planteada, se identificará en el cargo y descargo y en la partida doble los rasgos característicos que los vinculan a los arquetipos

${ }^{1}$ Un arquetipo es un patrón o imagen, producto intelectual del inconsciente colectivo, que permite ordenar los elementos psíquicos bajo ciertas imágenes, caracterizadas como arquetípicas, de tal forma que sólo se pueden reconocer los efectos que producen (Jung, 1969). El concepto de arquetipo, formulado por Jung, trasciende el sentido restringido del símbolo. Los arquetipos representan la posibilidad de que ciertas ideas, percepciones o acciones sucedan ante determinadas circunstancias del entorno y predisponen al individuo a enfocar su vida y vivirla de una determinada forma, de acuerdo con las pautas anticipadas previamente dispuestas por la psique (Stevens, 1994). sociales propios de la manera de razonar del hombre medieval y del renacentista, respectivamente. Dado el componente cultural y sociológico de la investigación, se usa una metodología comparativa para analizar dichos rasgos sobre fuentes primarias de la literatura de los periodos históricos objeto de estudio y fuentes secundarias elaboradas por historiadores (Chan, 2017).

Teniendo en cuenta que el paso de la Edad Media a la Edad Moderna supuso un cambio en el pensamiento religioso, político, social y económico en Europa y en sus manifestaciones técnicas y artísticas se estudiará el entorno de cada época. Además, se buscarán los rasgos en los registros contables de cargo y descargo y de partida doble, empleando una metodología cualitativa que permita llegar a conclusiones respecto a cada modo de registro. El resultado del trabajo avalará que la representación del método contable surge de la forma de pensar propia del ambiente donde se desarrolla. Esta idea podría extrapolarse al contexto actual y permitirá en el futuro reflexionar sobre las formas contables a las que conducirán los arquetipos mentales existentes, donde la sociedad de la información y la rendición de cuentas a stakeholders parece marcar la relación entre la información contable y la no financiera. En el segundo apartado del trabajo, se repasa el estado de la cuestión. En el apartado tercero, se muestran las características del pensamiento económico y contable en las edades Media y Moderna. En el cuarto, se estudia su influencia en los métodos contables y se finaliza con una discusión y conclusiones.

\section{Estado de la cuestión}

El cargo y descargo y la partida doble han sido analizados, tanto en el contexto general como particular (Lemarchand, 1994; Álvarez-Dardet \& Capelo, 2003; Sangster \& Rossi, 2018), considerando tanto sus aportaciones técnicas como sus funciones en la práctica social (Laughlin, 1988; Napier, 2006). En este ámbito, los trabajos analizados pueden ser agrupados en dos líneas: una, en la que se muestra la influencia de la contabilidad en el entorno; y otra, en la que el entorno influye en la contabilidad. En la primera, la contabilidad se considera por su contribución al contexto en el que se desarrolla, los trabajos más influyentes se han centrado en el estudio de la partida doble como instrumento de control capaz de influir en el entorno por su racionalidad y que finalmente facilitó la aparición del capitalismo. Desde la sociología, autores como Sombart (1902 y 1930) asocian la aparición de la partida doble al origen del capitalismo con el Renacimiento italiano cuando se separaron las cuentas de los negocios de la de los propietarios. También, este autor (1902) y Schumpeter (1934) señalaron su uso como un medio racional para orientar la economía a través de la toma de decisiones que facilitó el crecimiento de los negocios. Weber (1927; y 1956, p. 70) ve necesario para el surgimiento del capitalismo, la necesidad de registrar el concepto de capital y el surgimiento de la partida doble, considerándolo como el método más desarrollado para poner de manifiesto la ficción de procesos de cambio que permitieran el control. Edwards (1989) explica la aparición de la partida doble por el incremento de las transacciones de crédito. Carruthers \& Espeland (1991, pp. 33 y 36) señalaron que la partida doble fue ideada para registrar transacciones de negocio, pero una vez establecida, alteró esas transacciones con cambios en la forma de interpretar y comprender los negocios.

Con respecto a la segunda línea, otros autores han mostrado la influencia del entorno en la contabilidad, de manera 
que un determinado entorno produce un sistema contable peculiar y, por el contrario, entornos diferentes producen sistemas contables diferentes. Laughlin (1987, p. 480) afirma que los sistemas contables deberían entenderse relacionados en el contexto en que se ubican. Hopwood (1990 y 1992) señala una interrelación entre contabilidad y economía. Así, fruto de esta interrelación, entre las funciones de la contabilidad está la de ser capaz de visibilizar conceptos y fenómenos abstractos como las creaciones del intelecto humano, razón por la cual la contabilidad encierra en sus registros los datos que facilitan su observación, justificando su papel en aspectos sociales y organizativos (Hopwood, 1990, p. 10). Esto es posible porque la técnica contable está inspirada por la racionalidad y el funcionamiento económico y empresarial, observándose una relación causa-efecto recíproca entre contabilidad y entorno (Hopwood, 1987, p. 210). Basándose en la influencia del entorno en la contabilidad, Bhimani (1994) estudia los cambios contables como consecuencia de los cambios en la transición del Mercantilismo al Liberalismo económico en los siglos XVIII y XIX. Por su parte Chan (2017) señala las interconexiones entre los sistemas contables y los factores culturales en China, para interpretar la información financiera y promover cambios que contribuyan a establecer estrategias para hacer negocios.

Tomando como base la influencia del entorno en la contabilidad, algunos autores han explicado la aparición de la partida doble. Hoskin \& Macve (1986) (ver también Macve 1996), vieron el origen de la partida doble en los avances educativos surgidos en la Universidad medieval a partir del siglo XI. Thompson (1991, p. 584), intentando comprender el cómo emergió la contabilidad moderna, explica que hubo cambios en la Universidad del siglo XV que enfatizaron una creencia en un orden santificado por Dios, lo que a su vez explica por qué Pacioli, un profesor de matemáticas, pudo escribir su Summa. Trevor-Roper (1965) lo explica por la comunicación que, a partir del siglo XIII y a través de caravanas comerciales, tuvo Europa y el lejano Oriente con la aquiescencia del imperio mongol. Sin embargo, Zaid (2000) y Nobes \& Zaid (2001) lo ven como consecuencia del contacto de Italia con el mundo islámico.

Pese a la vinculación entre contabilidad y entorno, en pocas ocasiones los trabajos analizan las peculiaridades de ambos métodos buscando rasgos que hagan referencia al pensamiento ético, filosófico o religioso. En este sentido, Carmona \& Ezzamel (2006) señalan una falta de trabajos sobre asuntos tales como la interrelación entre las cuestiones éticas en diferentes contextos religiosos con la contabilidad; el papel que la contabilidad tiene en la representación de estos aspectos; y la contribución de la contabilidad a reforzar una religión o ética. Igualmente, Cordery (2015) insiste en la escasez de estudios con una perspectiva macro que traten la influencia de la religión en la contabilidad de las instituciones.

La literatura muestra que la contabilidad, al margen de sus condiciones técnicas, es una práctica que por su relación con la sociedad es capaz de influir en su entorno y ser influida por el mismo. En consecuencia, la contabilidad pasa a ser una técnica también influida por el pensamiento ético y religioso (Carmona \& Ezzamel, 2006). De esta manera, puesta de manifiesto la influencia recíproca entre la contabilidad y contexto en el que se desarrolla y la escasez de trabajos que den respuesta a la cuestión planteada, a continuación, este trabajo se centra en explicar el cambio en el sistema contable como consecuencia del cambio filosófico y teológico que se produjo con el paso de la Edad Media al Renacimiento.

\section{Pensamiento económico y contable en las edades me- dia y moderna}

La contabilidad es un lenguaje que activa un proceso cognitivo para adquirir e interpretar datos del entorno económico, por ello, en la literatura se recoge que ésta facilita al usuario modificar la representación inicial hasta llegar a una imagen final de modo que es capaz de construirse una idea de cómo es la realidad (Busch, 1997, pp. 39-41). En este proceso se advierte que existe una correspondencia entre ésta y los arquetipos mentales ${ }^{2}$ de la persona, por ello, este trabajo pretende analizar cómo inciden los factores filosóficos, ético-morales y religiosos del individuo en la construcción de la realidad económica a través del método contable (Carmona \& Ezzamel, 2006).

\subsection{Factores ético-religiosos, sociales y económicos en la Edad Media y Moderna}

La Edad Media, uno de los períodos históricos más largos, se considera inaugurada con la desintegración del Imperio Romano de Occidente en el siglo V, y comprende la Alta Edad Media (siglos V-X) y la Baja Edad Media (siglos XI-XV). En la Baja Edad Media se asiste a la consolidación y posterior declive del sistema feudal, donde un noble se constituía en dueño de un territorio al que sus habitantes rendían pleitesía y lo retribuían a cambio de protección. Con el paso del tiempo, la ciudad adquiere protagonismo como consecuencia del crecimiento demográfico y la proliferación de actividades económicas no asociadas a la agricultura, como la artesanía y los negocios, que a su vez dieron lugar a cambios que se reforzarán en la Edad Moderna. Pese a estos conatos de cambio, la sociedad seguía estructurándose como en la Alta Edad Media, de forma piramidal en tres estamentos: dos de ellos privilegiados, la nobleza y el clero; y el pueblo llano, que trabajaba en su mayoría la tierra propiedad de los señores feudales, propiciándose así desigualdades en la distribución de la riqueza, no sólo entre éstos sino dentro de cada sector social y también en el ámbito del campo y la ciudad (Almenar et al., 2017).

Entre el XI y XII, adquirieron protagonismo las Cruzadas, cuyo objetivo era recuperar el control europeo de Tierra Santa. Estas motivaciones y otros factores hicieron que la Iglesia adquiriera mayor autonomía institucional, influyendo en el orden político, militar, social y educativo. El pensamiento estaba basado en el Teocentrismo por el que las personas ponían a Dios como principio y fin del Universo. Se veía a Dios como Creador, Señor ${ }^{3}$ y Juez ante quien debía comparecer la humanidad, un pensamiento que incluso sirvió de base para entender los textos jurídicos elaborados en esta época (Martínez Martínez, 2010, p. 307).

La influencia del pensamiento religioso en la Edad Media se vio reforzada por la cercanía que la sociedad europea tenía con la muerte, motivada por las graves crisis de mortalidad como pestes y guerras. En virtud a ello, el individuo consideraba su vida en la tierra como de transición hacia la eternidad, condicionada a una "rendición de cuentas" ante un Dios, Señor y Juez, que se plasmaba al final de su vida en un juicio particular. La sentencia, favorable o no, lo sería en función de sus actos, de su capacidad para elegir libremente entre el

${ }^{2} \mathrm{El}$ inconsciente colectivo está compuesto por arquetipos conformados por imágenes primordiales que provienen de la historia de la humanidad. Jun definió los arquetipos como factores y motivos que ordenan los elementos psíquicos en ciertas imágenes, y las representaciones arquetípicas son las variaciones personales que se remiten a esas formas básicas que son los arquetipos en sí (Alonso González, 2004, p. 60).

3 “Feliz la nación cuyo Dios es el Señor" (Biblia, Salmo 33, 12). 
bien y el mal y bajo su responsabilidad. Así pues, la justicia divina inspiraba angustia y temor, pero también salvación, un destino eterno que será decidido en el juicio final donde la humanidad será separada en elegidos y condenados, un tema recurrente en el arte medieval (Ruíz Gallegos, 2010).

El pensamiento medieval imperante fue la Escolástica, donde la razón quedaba subordinada a la fe, primando la Teología sobre la Filosofía. Esta forma de pensar, que había dominado la Baja Edad Media (siglos XI-XV), perduró en años posteriores. No hay que olvidar que, aunque para los historiadores en general, la Edad Media se da por finalizada en 1453 con la caída de Constantinopla, o en 1492 con el descubrimiento de América, no atiende a una fecha concreta, dejando en las instituciones y en el pensamiento colectivo elementos todavía vivos (Bennassar \& Jacquart, 2005, p. 11). De hecho, en los siglos XV y XVI la preocupación por la salvación y la mentalidad religiosa popular seguían guiando la mayoría de las actitudes y formas de vida de las personas.

A mediados del siglo XV, propiciado en parte por la modernización y progreso de la agricultura, se produjo el auge de la vida urbana y del comercio y la aparición de una clase social nueva, la burguesía, que iría desplazando a la nobleza y al clero en las decisiones políticas. En este contexto, la búsqueda de riqueza movió al hombre a acometer grandes empresas comerciales, toda una forma de pensar que recalará en el Mercantilismo, dónde el máximo interés de los negocios estaba en conseguir ganancias. Las ciudades europeas se convirtieron en el punto donde convergía el comercio. Esta prosperidad económica sirvió para financiar los grandes descubrimientos, alentar las artes y una primera revolución científica, lo que se tradujo en cambios sociales que trascendieron a todos los ámbitos (Burns, 2001, p. XVI). Con ello, las ramas más representativas del saber se orientaron a transmitir una idea de conjunto del universo donde todo estaba matemáticamente relacionado, siendo una de las figuras más representativas el ingeniero, pintor y escultor Leonardo Da Vinci (1452-1519).

En el camino a la modernidad, la Iglesia perdió protagonismo, sacudida por la Reforma y la Contrarreforma, percibiéndose en lo filosófico un afán por el conocimiento y la lectura directa de los textos clásicos (ad fontes sobre la auctoritas suprema de sus traductores), en el marco de un interés filológico y teológico que caracterizó el Humanismo Renacentista, a través del cual el hombre empezaba liberarse de los anclajes de una teología que le sujetaba a una visión limitada y le impedía obtener sus propias conclusiones. El Humanismo aportó métodos y técnicas de crítica y depuración textual y supuso un contrapeso al pensamiento abstracto de la lógica, ya que los humanistas vincularon la vuelta a una supuesta “época dorada" de la antigüedad con la eliminación de la tradición medieval impuesta por la teología escolástica (Rummel, 2009, p. 281).

La Edad Moderna irrumpió como un despertar del ser humano a su propia perfección a través de un conocimiento de sí mismo y de su capacidad de contribuir, a veces combinando religiosidad y ciencia, a la creación de su propio entorno, que el hombre medieval había dejado casi por entero "en las manos" de Dios. El afán del hombre por contribuir, desde la libertad y como individuo con su propia perfección al desarrollo de su entorno se aprecia en La Utopía de Tomás Moro (1516), donde el autor concibe un lugar (Utopía), en el que los ciudadanos viven en armonía con una función concreta y complementaria del resto, cuyo objetivo es el bien común, la viva imagen de una sociedad perfecta pero utópica.

La Edad Media y Moderna presentan rasgos diferenciadores (ver Tabla 1) entre los cuales se han seleccionado algunos de los más representativos como indicadores de referencia a identificar posteriormente en los métodos contables.

Tabla 1. Rasgos identificadores del pensamiento de la Época

\begin{tabular}{|c|c|c|}
\hline $\begin{array}{l}\text { Conceptos } \\
\text { característicos }\end{array}$ & Edad Media & Renacimiento \\
\hline \multirow{2}{*}{ Filosofía } & Teocentrismo & Antropocentrismo \\
\hline & La Escolástica & Humanismo renacentista \\
\hline Filósofos & Tomás de Aquino & $\begin{array}{l}\text { Petrarca, Bocaccio, Tomás Moro, } \\
\text { Galileo, Kepler }\end{array}$ \\
\hline $\begin{array}{l}\text { Tratados } \\
\text { filosóficos }\end{array}$ & Summa Teológica & Utopía \\
\hline Ética / Moral & $\begin{array}{l}\text { Juicio final y respon- } \\
\text { sabilidad de los actos } \\
\text { realizados }\end{array}$ & $\begin{array}{l}\text { Descubrimiento, vuelta a los oríge- } \\
\text { nes, ad Fontes }\end{array}$ \\
\hline $\begin{array}{l}\text { Mentalidad } \\
\text { religiosa }\end{array}$ & $\begin{array}{l}\text { Distancia entre un } \\
\text { Dios todopoderoso y } \\
\text { el hombre }\end{array}$ & $\begin{array}{l}\text { El hombre, creado por Dios, es li- } \\
\text { bre y busca la armonía con el mis- } \\
\text { mo Dios }\end{array}$ \\
\hline Justicia & Conmutativa & Distributiva \\
\hline Sociedad & $\begin{array}{l}\text { Señor feudal, se le } \\
\text { rinde pleitesía para } \\
\text { recibir protección }\end{array}$ & $\begin{array}{l}\text { Vida urbana, ciudades más pobla- } \\
\text { das. Surge la burguesía }\end{array}$ \\
\hline El hombre & Vive aislado & Valora el relacionarse \\
\hline
\end{tabular}

De igual forma, al comparar dos obras de arte de estas épocas se pueden identificar los rasgos que las diferencian (ver Imagen 1), pues la evolución de los estilos en cuanto a las expresiones del hombre en las diversas épocas y civilizaciones, ha originado una gran variedad de maneras de abordar las obras de arte y consecuentemente su historia (Plazaola, 2015). Son esos rasgos los que se pueden asociar en dos momentos históricos que quedan caracterizados por formas diferentes de pensar (ver Tabla 2).

Imagen 1.

Imágenes representativas del Teocentrismo y Antropocentrismo

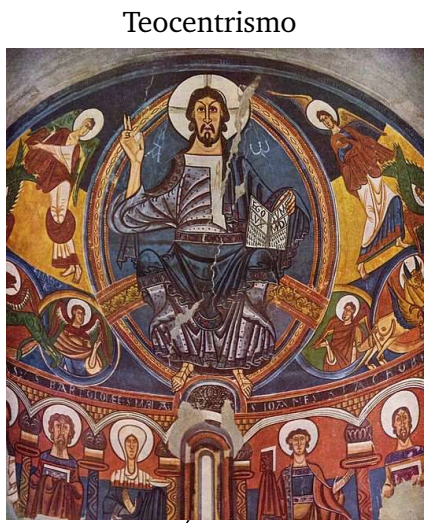

"El Juicio Final". Ápside de San Clemente de Taull. (Anónimo. 1123)
Antropocentrismo

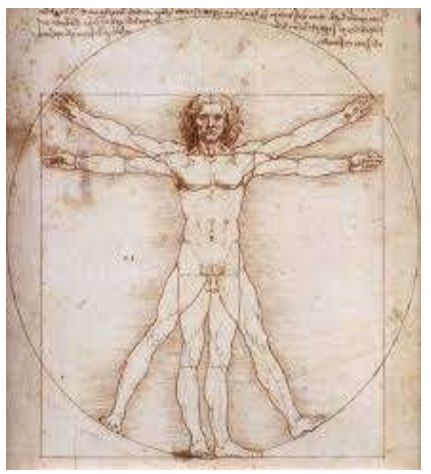

"El hombre de Vitruvio". Galería Académica de Venecia (Leonar do Da Vinci. Alrededor de 1490)

\subsection{La construcción contable de la realidad económica}

- Las relaciones principal-agente: gestión económica delegada y el cargo y descargo

En la Edad Media la microeconomía se asienta en operaciones económicas simples, fruto principalmente de la relación entre sujetos rentistas (como nobleza, clero y administración pública), que vivían de la explotación de derechos, muebles, inmuebles o propios, y terceros a los que se les había cedido éstos temporalmente para su administración. Este tipo 
Tabla 2. Rasgos del Arte de cada Época

\begin{tabular}{|c|c|c|}
\hline $\begin{array}{l}\text { Conceptos } \\
\text { característicos }\end{array}$ & Edad Media & Renacimiento \\
\hline Objetivo & Didáctico religioso & $\begin{array}{l}\text { Muestra un ideal de belleza, las } \\
\text { proporciones y la armonía }\end{array}$ \\
\hline Temas & Temas religiosos & También profanos \\
\hline Artistas & $\begin{array}{l}\text { En su mayor parte } \\
\text { anónimos }\end{array}$ & $\begin{array}{l}\text { Los artistas son conocidos, gozan } \\
\text { de un cierto prestigio social }\end{array}$ \\
\hline Se persigue & $\begin{array}{l}\text { Fidelidad a los princi- } \\
\text { pios del arte }\end{array}$ & $\begin{array}{l}\text { Búsqueda de la belleza y perfec- } \\
\text { ción }\end{array}$ \\
\hline El ser humano & Secundario & Es la obra más perfecta de Dios \\
\hline Autor & $\begin{array}{l}\text { La mayoría, descono- } \\
\text { cidos }\end{array}$ & Autores famosos \\
\hline $\begin{array}{l}\text { Dimensiones / } \\
\text { Perspectiva }\end{array}$ & $\begin{array}{l}\text { Dos / No hay perspec- } \\
\text { tiva / no hay fondo ni } \\
\text { paisaje }\end{array}$ & $\begin{array}{l}\text { Tres / Hay perspectiva, fondo y } \\
\text { paisaje }\end{array}$ \\
\hline
\end{tabular}

Fuente: Elaboración propia en base a VVAA (1987, 6, 142, 74, 84 y 67).

de operaciones se enmarca en relación principal-agente que orienta el comportamiento de los agentes hacia los objetivos del principal, entendiéndose la organización como una ficción legal en cuyo seno surgen relaciones contractuales (Jensen y Meckling, 1976, p. 311). En este contexto, la contabilidad registraba la actividad del agente, gestor del patrimonio del principal, que cada cierto tiempo debía rendir cuentas por cargo y descargo.

Al cargo y descargo se refiere Diego del Castillo (1522, 3v) en su Tratado de Cuentas (1522), al exponer que existían tres formas de dar cuenta y razón: a) data y recibo; b) debe y debe haber; y c) cargo y data o descargo (Vlaemminck, 1961). Este último procedimiento permitía "escuchar" las cuentas en un orden lógico (Noke, 1981, p. 151) en el que el administrador era cargado con las cantidades de las que era responsable y descargado de los pagos legítimos, obteniéndose por diferencia de los dos términos el "alcance" o importe que el administrador debía devolver al señor o mantener en el cargo para el siguiente ejercicio (Baxter, 1980, p. 69).

\section{- Los hombres de negocios y la partida doble}

En la Edad Moderna la proliferación de hombres de negocios y mercaderes dinamizó la economía y las operaciones se hicieron más complejas en consonancia con los cambios en la distribución de la producción y la propiedad. El sujeto económico era artífice y propietario de un negocio dinámico sobre el que debía tener un conocimiento completo y ordenado que sólo le podía proporcionar la partida doble. Además, en este tiempo los negocios dependían en gran medida del crédito, de manera que el método de la partida doble con el uso de cuentas personales permitió a sus propietarios conocer el estado de su deuda y operar de manera eficiente (Sangster, 2016).

Para Pacioli, autor de la Summa de Arithmetica, Geometria, Proportioni et Proportionalita (1494), la partida doble consistía en anotar dos veces la misma cosa y por igual importe en el libro manual o diario cronológicamente y en el libro mayor, también dos veces, una en el "debe" y otra en el "haber" de las cuentas que intervenían en la operación. Estas cuentas representan los elementos que interactuaban en un negocio (personas, objetos o propiedades) con dos partes en su versión deudora o acreedora (debe y haber), obteniéndose el estado o saldo de la cuenta en cualquier momento por diferencia entre ambas partes. De esta manera, el saldo ponía el "debe" y el "haber" de cada cuenta en equilibrio o igualdad numérica.

En aplicación al método, en cada operación se representa el origen y su efecto y la cuantía idéntica en ambos, quedando cada uno subordinado a la existencia del otro, por ello cada partida tiene su contrapartida. La representación del movimiento descansa en el principio de causalidad creando una relación entre las cuentas, cuyo estado va cambiando para dar mayor visión de movimiento del negocio. En base a ello, la pretensión es recoger la circulación de valor, por lo que se fija la atención en el proceso en el cual tiene lugar la acción y en el valor que se da o recibe a través de la posición sintáctica de débito y crédito. Este proceso contable transforma dos transacciones inter-unidad en una intra-unidad (López \& Rodríguez, 2003, p. 70). La Tabla 3 muestra rasgos del contexto económico que facilitaban los métodos contables del cargo y descargo y de la partida doble.

Tabla 3. Rasgos Identificadores del Sistema Económico y Contable

\begin{tabular}{|c|c|c|}
\hline $\begin{array}{l}\text { Conceptos } \\
\text { característicos }\end{array}$ & Edad Media & Renacimiento \\
\hline \multirow{3}{*}{ Economía } & Básicamente agraria & $\begin{array}{l}\text { Urbana, comienzan a aparecer ac- } \\
\text { tividades manufactureras que faci- } \\
\text { litan el comercio }\end{array}$ \\
\hline & $\begin{array}{l}\text { Principalmente } \\
\text { rentista }\end{array}$ & $\begin{array}{l}\text { Comercio en ferias de grandes ciu- } \\
\text { dades }\end{array}$ \\
\hline & $\begin{array}{l}\text { Prohibición de la usu- } \\
\text { ra }\end{array}$ & Búsqueda del beneficio \\
\hline \multirow{2}{*}{$\begin{array}{l}\text { Predomina una } \\
\text { población }\end{array}$} & & Aparecen mercaderes \\
\hline & Campesina. & $\begin{array}{l}\text { Aparece una burguesía con interés } \\
\text { en la cultura }\end{array}$ \\
\hline $\begin{array}{l}\text { Sistema } \\
\text { Económico }\end{array}$ & Feudalismo & Mercantilismo \\
\hline $\begin{array}{l}\text { Relaciones } \\
\text { económicas }\end{array}$ & Simples & Más complejas \\
\hline $\begin{array}{l}\text { Método } \\
\text { contable }\end{array}$ & Cargo y descargo & Aparece la partida doble \\
\hline
\end{tabular}

Fuente: Elaboración propia

\section{El método contable como expresión del pensamiento}

Como se ha puesto de manifiesto, Edad Media y Edad Moderna constituyeron dos formas de pensar y de concebir las relaciones sociales, económicas, la contabilidad y los métodos contables. Así pues, el cargo y descargo y la partida doble perseguían el mismo fin, que era determinar la posición deudora o acreedora entre dos sujetos (principal y agente) en el caso del cargo y descargo (o data); y entre el sujeto o sujetos propietarios del negocio con otros (deudores o acreedores) en la partida doble. En otras palabras, se trataba en el primer caso de la elaboración de una cuenta única y en el segundo de la interacción de varias cuentas.

Es en la forma de representación y no en el resultado o saldo de la/s cuenta/s donde se buscaba identificar la imagen que cada uno de los métodos contables pretendía evocar. Para lograr este propósito se analizarán los elementos (términos, relaciones y expresiones) con los que cada uno de ellos presenta la realidad económica, transmite la información y la caracteriza, ya que se intuye una relación directa entre la forma de percibir la realidad y la concepción económica que de ésta se tiene. Es decir, se pretende discernir las interconexiones entre los métodos contables y los factores socio-económicos de la Edad Media y del Renacimiento.

\subsection{El cargo y descargo y el pensamiento medieval}

Como se ha apuntado, la Escolástica dominó los estudios generales que dieron lugar a las universidades europeas, en especial entre mediados del siglo XI y del XV. La base de su desarrollo estaba en subordinar los aspectos materiales de 
la vida a la salvación del mundo, por lo que la economía no se entendía como una disciplina independiente, sino como un apéndice de la ética y las leyes (De Roover, 1983, p. 90). Las ideas y problemas económicos, como por ejemplo los préstamos de dinero, sólo tenían sentido como parte de una perspectiva más general, ya que la economía no constituía un campo que mereciera ser considerado separadamente, por lo que las soluciones a los problemas económicos eran analizados desde la teología, la filosofía, la moral, la política o las leyes, siendo considerados como meros aspectos de la vida social, especialmente relacionados con el comportamiento humano (Chaplygina \& Lapidus, 2016, p. 20). Desde esta perspectiva, los escolásticos se preocuparon más por los comportamientos individuales de los hombres de negocios que por la economía en su conjunto. Muchos de los intelectuales, en su mayoría eclesiásticos y confesores, mostraron inquietud por las implicaciones morales del comportamiento provocado por las innovaciones del comercio incipiente (Trifilio, 2018, p. 2). Otros autores constatan la frecuencia en que los asuntos económicos se citaban en las guías para confesores (De Roover, 1983, p. 91), llegando a ser calificado el manual del confesor como un libro de análisis económico (Vilar, 1982, p. 217).

El afán de los escolásticos por preservar la moral de la economía avivó el concepto de Justicia, una de las virtudes cardinales del cristiano. Esta visión de la justicia era deudora de la concepción aristotélica y de la filosofía tomista del siglo XIII, donde se pensaba que el hombre era un ser que vive en sociedad y en ese entorno de relaciones la justicia evita conflictos, teniendo como materia propia aquellas cosas que se refieren a otro, advirtiéndose una relación directa entre la Ley Natural y el Derecho Divino. En su concepción clásica, la justicia tenía como fin determinar y decir lo que era de cada uno. Por extensión, en el comercio, "lo justo" era lo que el deudor debía dar al acreedor y que a la vez constituía el derecho de este último. Dicho de otro modo, lo dado debía ser igual a lo debido, entonces determinar lo justo consistía en precisar lo igual a lo debido, ya que la igualdad en el contexto de justicia correctiva es una proporción aritmética entre dos términos (Englard, 2009, p. 8).

En definitiva, las relaciones económicas entre individuos debían someterse a reglas que buscasen la justicia fundamentada en la igualdad o equivalencia de los bienes intercambiados, donde ninguna de las partes debía sufrir pérdida. En ello era de aplicación la denominada justicia conmutativa o justicia propiamente dicha, que tiene por objeto el derecho de propiedad, donde se prevé la igualdad de una cosa por otra (Aquino, 1265-1274, p. 264), con una visión de igualdad aritmética. De acuerdo con Jones (1985), en este contexto el sistema de cargo y descargo era suficiente para asegurar la rendición de cuentas del agente sobre su administración. Otra cosa era la justicia distributiva, con la que se medía la igualdad de proporciones, la geométrica, y que se entendía en relación a la distribución de los bienes comunes entre cada persona dentro de un ambiente social en el que los bienes eran distribuidos de acuerdo al valor, condición o función de cada miembro del grupo (Trifilio, 2018, p. 3). De esta manera, el objetivo de la justicia conmutativa estaría en permitir al hombre obtener las cosas sin disminuir injustamente la parte de riqueza que corresponde a los demás (Gordley, 2013, p. 17).

Así, es posible establecer una relación positiva entre la justicia conmutativa, la equidad y los rasgos característicos de la cuenta y razón por cargo y descargo. En ese caso, la hipótesis sobre la que descansa dicho procedimiento es el criterio empleado para tipificar los hechos del principal y del agente: los actos a favor del principal y en contra del agente (obligación del agente con el principal) se recogían en el cargo de la cuenta; y los actos a favor del agente y en contra del principal (obligación del principal con el agente) en el descargo. Finalmente, la justicia se concretaba en el alcance, donde se "sentenciaba" la gestión o la relación contractual entre las partes, a favor de uno y en contra de otro o igual, de lo que se infiere que prevalecía el fin de juzgar la actuación del agente sobre el de incidir en una gestión ya cerrada. Las garantías en la composición de la cuenta (orden expositivo y descripción detallada de los elementos a valorar y la revisión de los contadores), así como la presencia de un notario y testigos al cierre confirmaban el componente jurídico del registro. Así lo reconoce Del Castillo (1522, 26v-27r) al hablar del cargo y descargo: "Y también las partes las an por buenas firmaran este autcto: porque puesto que tenga este aucto semejança de juyzio o de aucto de juyzios tiene fuerça de pacto y es menester que se firme por leyes de los reynos", lo que explicaría también que al verse el cierre de la cuenta como un juicio el autor lo concibiera como una forma de representación de la cuenta "algo grossera" (1522, 10v).

Para comprender el papel del cargo y descargo en la concepción ética y moral de la economía, es conveniente centrar la atención en su función como mecanismo de control del principal sobre un agente encargado de rendirle cuentas, hecho que guarda similitud con la rendición de cuentas que el creyente-siervo debe hacer ante Dios-Señor al final de su vida (Villaluenga, 2013), sobre lo que se encuentran múltiples referencias en Los Evangelios. ${ }^{4}$ En todos ellos, al final de la vida Dios (el Señor) pediría cuenta individual al cristiano (siervo) de los dones y las gracias concedidas, que no son iguales para todos, de cuya fructificación y uso éste quedará obligado a responder con las obras, de manera que cuanto mayor fuera el cargo mayor debía ser el descargo. En este acto se aprecian los elementos característicos del procedimiento de cargo y descargo: la delegación del dueño (Dios-Señor) en el agente (siervo), la llamada a rendir la cuenta final, la justificación de los actos y la sentencia.

A fin de infundir responsabilidad, la rendición de cuentas también ha sido utilizada para representar el sacramento de la confesión (Aho, 2005, p. 28), inculcando así al individuo una conducta cristiana en previsión a lograr una sentencia favorable en un supuesto "Juicio Final". Con este objeto, en los países de tradición más cristiana, proliferaron los libros de meditación y oración entre los siglos XVI y XVIII, en los que se pueden encontrar referencias explícitas a la rendición de cuentas en términos de cargo y descargo (ver Tabla 4).

En base a lo expuesto, es posible establecer una relación entre el cargo y descargo y la imagen de juicio que podía representar, percibiéndose la realidad económica desde una perspectiva más cercana al ámbito jurídico (Villaluenga \& Llibrer, 2019) y de responsabilidad que desde una óptica económica (Baxter, 1980, p. 71). Además, al representarse en el cargo y descargo una relación de agencia, se percibe una distancia entre el propietario de las rentas o de la propiedad (Señor) y su gestión, que había sido entregada a un agente (Siervo). Esta distancia es un rasgo característico de la mentalidad medieval que puede apreciarse en la distancia que se percibía entre el señor y los siervos y también, entre Dios y el creyente. En esta línea, otro rasgo que permite confirmar la imagen de juicio es que en la rendición de las cuentas junto a principal y agente estaban presentes un notario y dos testigos, por lo que el cargo y descargo evoca con mayor facilidad la fi-

${ }^{4}$ Hay varios pasajes en los Evangelios que hacen referencia al creyente como siervo (Lucas 17:7-10), y a ajustar cuentas (Mateo 19, 23-35; Mateo 25,14-30; Lucas 12,42-48; Lucas 16,1-13). 
Tabla 4. Referencias a la Rendición de Cuentas en Libros de Meditación

\begin{tabular}{|c|c|}
\hline Autores (año) & Referencias \\
\hline $\begin{array}{l}\text { Fray Luis de } \\
\text { León }(1527, \text { p. } \\
\text { 227) }\end{array}$ & $\begin{array}{l}\text { En un comentario al Libro de Job, en el momento en } \\
\text { que Dios aparta a éste del juicio, el autor señala que no } \\
\text { hubo "[...] ni descargo, ni condenación, ni ninguna otra } \\
\text { cosa de las que son propias al tribunal y al juicio". }\end{array}$ \\
\hline $\begin{array}{l}\text { Racionero Pedro } \\
\text { Sánchez (1584, } \\
32 \mathrm{r}-\mathrm{v})\end{array}$ & $\begin{array}{l}\text { En un capítulo de su obra titulado "Cuenta estrecha que } \\
\text { a de dar el que recibe mucho", pone de manifiesto el ma- } \\
\text { yor rigor con que se juzgará al que recibe mucho de } \\
\text { Dios aconsejando estar vigilante, pues "[...] no se pue- } \\
\text { de saber que tal será la cuenta que se ha de dar a Dios } \\
\text { destos estados tan preeminentes, y como saldrá el cargo } \\
\text { y descargo". }\end{array}$ \\
\hline $\begin{array}{l}\text { Rodríguez de } \\
\text { Monforte (1584, } \\
\text { p. 191) }\end{array}$ & $\begin{array}{l}\text { Identifica en ese juicio "El cargo que nos haze Dios, es por } \\
\text { los libros de su Ley, que estando cerrada la gloria por la } \\
\text { culpa, él la abrió con su muerte, el descargo es las virtudes, } \\
\text { para que en fé de ellas se les dé à los Santos como Corona } \\
\text { el Cielo". }\end{array}$ \\
\hline $\begin{array}{l}\text { Ussher } \\
154)\end{array}$ & $\begin{array}{l}\text { "¿ Cuál es el efecto de la conciencia culpable? Causa en el } \\
\text { hombre una mentira cuando nadie le persigue y le hace } \\
\text { sentir temeroso de caer (...) aunque lo conozcamos o no, } \\
\text { permanece culpable como una deuda para el deudor (...) } \\
\text { y nunca podrá descargarla hasta que Dios lo tome sobre } \\
\text { su espalda cuando reconozca que no lo hizo bien". }\end{array}$ \\
\hline $\begin{array}{l}\text { Gother } \\
13)\end{array}$ & $\begin{array}{l}\text { "El descargo de la culpa de los pecados, también requiere } \\
\text { severas penas por el descargo de la deuda temporal del } \\
\text { castigo, debido a la divina justicia (...) los trabajos ade- } \\
\text { cuados que normalmente requieren obtener indulgencias } \\
\text { son rezar, visitar iglesias, confesión, comunión...". }\end{array}$ \\
\hline
\end{tabular}

nalidad de juzgar la actuación del agente que la de utilizar la contabilidad para una gestión eficiente. El cargo y descargo se asentaría sobre el concepto de justicia conmutativa nacido de un arquetipo mental propiciado, entre otros, por los escolásticos e instrumentado en una visión de igualdad aritmética, que pretendía estimar la cantidad que igualaba las imputables al principal o al agente antes de finalizar su relación contractual, presentándose la cuenta en forma de un juicio de partes.

\subsection{La partida doble y el pensamiento renacentista}

El Humanismo renacentista permitió desligar los asuntos básicos de la perspectiva teológica y enlazarlos con el pensamiento científico. Mientras que en algunos lugares de Europa triunfaba la Escolástica, en otros se imponía el Mercantilismo. Según De Roover (1983, p. 110), en contraposición a la Escolástica, desde el Mercantilismo se concebía la economía como amoral, no se repudiaba la usura, ni se concebía uniformidad en la doctrina o el método; y puesto que el comercio no tenía alma ni los individuos contaban, tampoco cabía perturbarse por cuestiones morales. De hecho, según Galbraith (1989, p. 49), los mercaderes de este tiempo eran "acomodaticios" en asuntos de conciencia.

El Renacimiento ligado al Humanismo, permitió el desarrollo de un pensamiento científico, donde la ciencia, la razón y el orden lo invadían todo, se recuperaba el sentido clásico de la belleza; y las matemáticas, consideradas como una ciencia fundamental y divina, sintetizaban la exegesis de la naturaleza a través del uso de las proporciones para el estudio de cualquier fenómeno. La proporcionalidad, entendida como conformidad o proporción de las partes con el todo y de éstas entre sí, pasó a constituir la base de cualquier estudio artístico (como la arquitectura, la pintura o la música) o científico (como la astronomía, las matemáticas o la geografía). En este sentido, una obra de referencia fue De Divina Proportione (1509) del franciscano, profesor y matemático Fray Luca Pacioli, donde se abordaba un tema que atañía a todas las ciencias y a la concepción del Universo que obsesio- naba al hombre ${ }^{5}$. El autor ya había tratado este tema en su Summa (1494), que los entendidos consideran la enciclopedia de los matemáticos (Yamey, 1994; Grendler, 2002), cuyo Título IX Tratado XI, "De Computis", está dedicado al método contable por partida doble, una publicación nada casual, si se considera la necesidad de los conocimientos matemáticos previos para el aprendizaje del método.

El pensamiento económico también quedó sometido al universo matemático, donde la Aritmética se asoció al uso de los números arábigos, jugando un papel fundamental en el comercio. Y así, junto a la proliferación de las escuelas de ábaco, se publicaron tratados de Aritmética con una temática común. Esta interrelación entre comercio y matemáticas era tal que en las escuelas mercantiles muchos de los problemas tenían como fin determinar el valor exacto de los bienes dentro de una transacción, ya que el valor era un concepto 'borroso' y subjetivo que requería de múltiples aproximaciones y cálculos relacionados con el tipo de cambio de las unidades de conversión que podía diferir de una ciudad a otra en un intento de dar solución a problemas contables y comerciales (Heeffer, 2011, p. 124). Por su parte, Scorgie (1989) afirma que los números eran más conocidos en el comercio que en las matemáticas propiamente dichas, al estar ya presentes en la Arithmética de Pacioli a través de sus doce reglas para la resta, lo que tampoco hace extraño su aplicación en la partida doble.

De acuerdo a lo anterior, se puede señalar que la transición de la Edad Media a la Moderna vino marcada por el Humanismo, movimiento intelectual que rompió con las tradiciones escolásticas exaltando al hombre y la razón, aspectos clave donde se asentó el Renacimiento. Esta corriente de pensamiento impulsó la ciencia y con ella las matemáticas en todos los ámbitos del saber, incluido el comercio, donde el Mercantilismo abrió paso al capitalismo y a la necesidad de obras de matemáticas como la Summa, que daría forma definitiva a la Aritmética italiana (Rojas, 2019, p. 41).

En definitiva, es posible establecer una relación entre el Humanismo $^{6}$, el Mercantilismo ${ }^{7}$, las matemáticas y los rasgos característicos de la partida doble. De los aspectos mencionados, es en la relación de la partida doble con el sentido de la proporcionalidad y las matemáticas donde el estudio de la forma de representación o del diseño del método adquiere su máxima significación. La simetría, el equilibrio, la igualdad y la proporción jugaron un papel clave en el desarrollo de la partida doble ya que la precisión y elegancia matemática del método fue un atractivo para los profesores y los contadores profesionales (Derks, 2008, p. 188). El propio Pacioli (1494, p. 18) consideraba el cálculo matemático y el orden como dos de las tres cosas que, además del dinero, precisaba un buen mercader. Todo ello son conocimientos que se dan en la composición axiomática del método (Sangster, 2018). De hecho, Carley (1894) afirma que en la partida doble las matemáticas juegan un papel fundamental, cuestión a veces desconocida por los contables. Ellerman (1985) opina que la partida doble se basa en una construcción matemática bien conocida

${ }^{5}$ Según Sangster (2018, pp. 306 y 311), considerando la formación franciscana, humanista y matemática de Pacioli, éste pretendió con su obra educar a los comerciantes proporcionándoles las herramientas que necesitaban para acercarles a Dios. No en balde, las matemáticas eran consideradas una ciencia fundamental y divina capaz de revelar los secretos del Universo y mejorar la posición del hombre en el Universo a la vista de Dios.

${ }^{6}$ McCarthy, Sangster, \& Stoner (2008), estudiando la Summa, concluyen que Pacioli supo reflejar su formación y su compromiso con el Humanismo, a través del idioma, el estilo literario, las referencias y las ilustraciones.

${ }^{7}$ El tratado de Pacioli, no sólo estaba destinado a ser leído y utilizado por comerciantes, sino que fue diseñado para ellos (Sangster, Stoner, \& Mc Carthy, 2008), de lo que se infiere el compromiso del método con las necesidades de los mercaderes. 
del álgebra de pregrado: el grupo de diferencias en el que los números enteros se representan como clases de equivalencia de pares ordenados de números naturales. Entre las últimas aportaciones a esta cuestión, Sangster (2018) prueba que Pacioli se inspiró en Euclides para componer el método, así como en una lógica simple basada en un enfoque, términos y proposiciones categóricas, donde se presentan inicialmente cinco axiomas para demostrar cómo funciona el método. El más evidente, señala, que lo que se registra dos veces verifica la verdad de la información.

Teniendo presente que la base del método era el doble registro de cualquier operación en el manual o diario cronológicamente y en el debe y haber de las respectivas cuentas en el libro mayor. Estos dos términos, "debe" y "haber", eran consustanciales a cualquier operación en la que además siempre participaban al menos dos sujetos, existiendo en todo caso una dualidad o doble dimensión objetiva y observable, una de tipo económico y otra de tipo financiero, ambas de la misma cuantía.

Partiendo de este orden, con cada transacción económica los elementos variaban continuamente su saldo, apoyándose sobre un algoritmo lógico que pone énfasis en la variación que sufren los objetos afectados fruto de la circulación económica, teniendo la capacidad de mostrar el movimiento, al igual que se aprecia en las obras de arte renacentistas. La idea de movimiento y la relación entre los sujetos se lograba con el uso de las preposiciones " $a$ " y"por" en la redacción de los registros (López Pérez, 1999, p. 462), utilizados para la construcción de los axiomas y teoremas que fundamentan matemáticamente el método (Sangster, 2018, p. 308). Mientras, la precisión, el rigor y la exactitud se lograba con los numerales (López \& Rodríguez, 2003, p. 70). Con todo ello, el movimiento en los saldos de las cuentas se transfería a la ecuación básica que equilibraba el negocio, mostrando la situación patrimonial.

Aplicando el método de la partida doble, la diferencia entre los sumatorios de las cuentas de saldo deudor y acreedor daba lugar al patrimonio, un concepto abstracto para el que no existía una cuenta concreta creándose la cuenta capital, esencia del método y que supuso un salto conceptual decisivo. Esta cuenta, inexistente antes de la invención de la partida doble, posibilitó y estimuló que se crearan ideas inherentes a un sistema capitalista (Sombart, 1953, 38), que en la literatura se atribuye a los cálculos matemáticos (Sombart, 1930; Bryer, 2000a, 2000b; Toms, 2010) y que permitían modelizar la realidad económica percibida, sobre todo en cuestiones antes inexistentes como el beneficio.

La partida doble se constituyó como un conjunto completo y "redondo" de registros ordenados convenientemente e interrelacionados que ofrecen una visión global y detallada de un negocio (Hernández Esteve, 2005, pp. 107-108). La contabilidad pasó a expresarse matemáticamente en una ecuación, en la que la suma algebraica de los elementos patrimoniales constituía el primer término, que es igual al segundo, compuesto de la cuenta de capital, una cuenta que puede dividirse en varias, denominadas cuentas de neto, (Hernández Esteve, 2017, p. 23). Dicha ecuación se expresó como activo igual a pasivo más neto. Esta modelización matemáti-

\footnotetext{
${ }^{8}$ En un contexto de competitividad en la que, como Weber (1956, pp. 70 71 ) indicaba, las empresas no sobreviven sin suficientes beneficios, la partida doble ofrecía una superioridad técnica ya que por medio de las cuentas se ponía como base la ficción de procesos de cambio entre las distintas secciones de una explotación permitiendo la concreción de dicho término abstracto. Los cargos y abonos en la cuenta de capital mostraban qué hechos lo aumentaban cuáles lo reducían, visualizando cuantitativamente el concepto abstracto de resultado, olvidándose las connotaciones jurídicas percibidas del cargo y descargo y revelando el fondo económico.
}

ca de la realidad empresarial, facilitada por la contabilidad, motivó que autores como Weber, Sombart y en menor grado Schumpeter, considerasen que la partida doble contribuyó al surgimiento de una cosmovisión racional (Carruthers \& Espeland, 1991, p. 33). La ecuación adquirió su máxima expresión en la composición del balance, cuya estructura permitía comprobar la correcta aplicación del método, acreditando si las dos partes, estas dos summe summarum, de la ecuación o del balance (activo y patrimonio más pasivo) eran iguales, queriendo conseguir el equilibrio, rasgo característico del Renacimiento, lo que significaba que el libro mayor estaba bien llevado y cerrado (Pacioli, 1494, p. 93). A lo mismo se refería el autor de uno de los primeros tratados contables por partida doble, Bartolomé Salvador de Solórzano (1590, 41r), en cuyo planteamiento no cabe lugar a duda sobre la orientación matemática del método cuando decía que hacer balance del libro de caxa era lo mismo que hacer la prueba de una cuenta de multiplicar para ver si estaba bien. Esta igualdad revela coordinación, de manera que cada cuenta representaba un aspecto parcial de la unidad económica dispersa que, vistas en su conjunto, permitían considerar la entidad como un todo.

En definitiva, la partida doble se asentaría sobre el concepto de la razón, el equilibrio, la proporción y el orden, conceptos nacidos de un arquetipo mental propiciado por los humanistas, que pretendía determinar matemáticamente el importe que equilibraría la relación de propietarios, deudores y acreedores, de manera que el debe sea igual al haber de cada cuenta. Finalmente, tras calcular el importe que iguala cada una de las cuentas, surge el balance donde las cuentas deudoras y acreedoras se equilibran con el resultado, beneficio o pérdida. La Tabla 5 se recoge rasgos del Humanismo Renacentista y su relación con la partida doble.

Tabla 5. Rasgos del Humanismo Renacentista y de la Partida Doble

\begin{tabular}{|c|c|}
\hline $\begin{array}{l}\text { Humanismo } \\
\text { renacentista }\end{array}$ & En la partida doble \\
\hline $\begin{array}{l}\text { Surge en ciudades } \\
\text { italianas }\end{array}$ & Favorecieron el comercio \\
\hline $\begin{array}{l}\text { Se valoran las fuentes } \\
\text { clásicas. Ad fontes }\end{array}$ & $\begin{array}{l}\text { Pacioli busca un argumento convincente de la legiti- } \\
\text { midad de las transacciones empelando los elemen- } \\
\text { tos de la retórica clásica }\end{array}$ \\
\hline Se valora la razón & $\begin{array}{l}\text { La cuenta de capital permite entender el concepto } \\
\text { abstracto de beneficio }\end{array}$ \\
\hline Justicia distributiva & $\begin{array}{l}\text { Era posible crear una cuenta a cada socio para impu- } \\
\text { tarle proporcionalmente sus ganancias }\end{array}$ \\
\hline $\begin{array}{l}\text { Se estudia el } \\
\text { Universo }\end{array}$ & $\begin{array}{l}\text { Registro de los elementos que interactúan (perso- } \\
\text { nas, objetos y propiedades) }\end{array}$ \\
\hline Simetría & $\begin{array}{l}\text { Dualidad: en libros (manual y mayor) y en cuentas } \\
\text { (cada asiento relaciona dos cuentas) }\end{array}$ \\
\hline \multirow{2}{*}{$\begin{array}{l}\text { Equilibrio y } \\
\text { proporción }\end{array}$} & $\begin{array}{l}\text { Equilibrio de las cuentas deudoras y acreedoras. } \\
\text { Igualdad de cargos y abonos }\end{array}$ \\
\hline & Summe summarum o balance de sumas y saldos \\
\hline Orden & Orden cronológico de los hechos y registros \\
\hline Claridad & $\begin{array}{l}\text { Errores se corrigen con contra asientos (no con ta- } \\
\text { chaduras) }\end{array}$ \\
\hline \multirow[b]{2}{*}{ Movimiento } & $\begin{array}{l}\text { Se percibe en las cuentas de mayor, se busca recoger } \\
\text { la circulación del valor }\end{array}$ \\
\hline & $\begin{array}{l}\text { Las preposiciones "a" y "por" evidencian el movi- } \\
\text { miento y el equilibrio constante. }\end{array}$ \\
\hline Exactitud & $\begin{array}{l}\text { Se lograba con los numerales, un solo importe en el } \\
\text { apunte del mayor unificaba prestación y contrapres- } \\
\text { tación }\end{array}$ \\
\hline
\end{tabular}

A la luz de lo planteado y de conformidad con la corriente de pensamiento imperante, se ve que la partida doble preten- 
día dar una respuesta matemática a los problemas comerciales consiguiendo determinar la verdad también a efectos de probanza. En la Tabla 6 se recogen las características de la contabilidad en ambos periodos.

Tabla 6. Características de los Métodos Contables

\begin{tabular}{|c|c|c|}
\hline $\begin{array}{l}\text { Método } \\
\text { contable }\end{array}$ & Cargo y descargo & Partida doble \\
\hline $\begin{array}{l}\text { Sujetos } \\
\text { implicados }\end{array}$ & Principal vs Agente & $\begin{array}{l}\text { Propietarios vs Deudores o } \\
\text { Acreedores }\end{array}$ \\
\hline Cuentas & Cuenta única & Varias cuentas \\
\hline $\begin{array}{l}\text { Importancia en } \\
\text { la rendición de } \\
\text { cuentas }\end{array}$ & $\begin{array}{l}\text { Saldo agente } \\
\text { (alcance). }\end{array}$ & $\begin{array}{l}\text { Equilibrio en cuentas, libros y } \\
\text { balance Summa Summarum }\end{array}$ \\
\hline Se valora & $\begin{array}{l}\text { La exactitud en el saldo } \\
\text { (alcance) }\end{array}$ & $\begin{array}{l}\text { La dualidad, proporcionalidad } \\
\text { y equilibrio (cuadre) }\end{array}$ \\
\hline Tratadista & Diego del Castillo & Luca Pacioli \\
\hline Tratado & Tratado de Cuentas. & $\begin{array}{l}\text { Summa de Arithmetica, Geome- } \\
\text { tria, Proportioni et Proportiona- } \\
\text { lita. }\end{array}$ \\
\hline Finalidad & Rendir cuentas & Determinar el resultado \\
\hline Fundamento & Jurídico & Matemático \\
\hline Justicia & Conmutativa & Distributiva y conmutativa \\
\hline Finalidad & $\begin{array}{l}\text { Justicia. Rendir cuen- } \\
\text { tas (también se rinde a } \\
\text { Dios en el Juicio Final) }\end{array}$ & $\begin{array}{l}\text { Perfección. Balance. Equilibrio } \\
\text { del debe y del haber (la cons- } \\
\text { trucción del propio entorno) }\end{array}$ \\
\hline
\end{tabular}

En la Imagen 2 se muestra la apariencia del cierre de una cuenta por cargo-descargo y por partida doble: la primera presenta el alcance a modo de sentencia; y la segunda el saldo para representar el equilibrio o igualdad numérica del "debe" y el "haber" de cada cuenta.

Imagen 2.

Cierre de una Cuenta por Cargo-Descargo y por Partida Doble

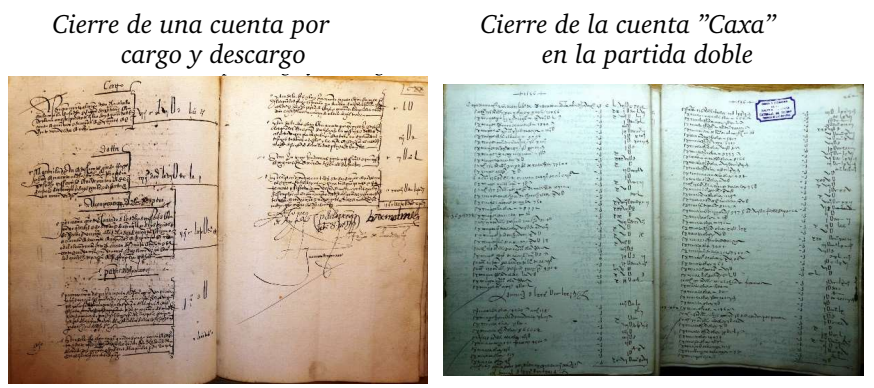

Fuente: ACT, OF-830, f. 119v-120r y OF-1264, f. 261v-262r.

\section{Discusión y conclusiones}

Como se recoge en la literatura, la contabilidad no es un fenómeno autónomo, sino que está influenciada por factores sociales, políticos y económicos (Hopwood, 1990, p. 8). La evolución del método contable de la partida simple a la doble se ha intentado explicar en la literatura por la influencia de diferentes factores, pero ninguno de ellos lo ha podido explicar satisfactoriamente de forma aislada (Oldroyd \& Dobie, 2009 , p. 108), ni tampoco hasta ahora se ha dado una razón clara que explique el uso de un método contable concreto como consecuencia a su vez de un cambio filosófico (Carmona \& Ezzamel, 2006). En este trabajo se ha podido comprobar que en un periodo histórico de grandes cambios como es el tránsito de la Edad Media a la Moderna (siglo XV), los rasgos filosóficos y religiosos que dominaron el pensamiento en cada época, Teocentrismo o Antropocentrismo, se manifiestan respectivamente en cada uno de los métodos contables imperantes, el cargo y descargo o la partida doble, como si de un estilo artístico se tratara.

Esta afirmación se sustenta en que el resultado de la cognición es el conocimiento de la realidad, en cuyo proceso intervienen multitud de factores que dirigen el pensamiento del individuo hacia un modo concreto de captar dicha realidad (López Pérez \& Rodríguez Ariza, 2002, p. 464). La contabilidad, como sistema de información, puede procesar los datos económicos de diferente modo, de ahí que ya Diego del Castillo en su Tratado de cuentas de 1522, señalara que el cargo y descargo y la partida doble pretendían el mismo fin, pero diferían en la manera de representación (Castillo, 1522, 3v).

Este trabajo demuestra que ambos métodos responden a las formas de pensamiento imperantes en el contexto histórico y filosófico en el que se desarrollaron. Por un lado, el cargo y descargo se asimila a una concepción teocéntrica, propia de la Edad Media, dominada por el pensamiento religioso y la idea de justicia divina. Esta concepción, contablemente implicaba mantener una igualdad aritmética que pretendía dar a cada uno lo que le correspondía y que se tradujo en la composición de la cuenta entre principal (Dios-Señor) y su agente (creyente-siervo) como un juicio de partes, en el que al enfrentar el cargo (bienes puestos a disposición del agente) y descargo (aprovechamiento de dichos bienes), se obtenía una sentencia (alcance o saldo). Por otro lado, la partida doble se relaciona con una concepción antropocéntrica, característica del humanismo renacentista. Con esta concepción, contablemente, predominaban los valores del equilibrio y proporción, dominado por las matemáticas, presentes en el uso de los numerales, que introducían precisión, rigor y exactitud al negocio; la dualidad en la composición de los asientos, que refleja movimiento; y el equilibrio y la proporcionalidad que otorga armonía al negocio, y en el que el propietario está en el centro del negocio mismo, buscando conocer su posición deudora o acreedora respecto a cada uno de sus elementos patrimoniales.

La visión tradicional de la contabilidad, como reflejo objetivo de la realidad, ha sido cuestionada desde el último tercio del siglo XX (Hopwood \& Miller, 1994). Con este trabajo se ha demostrado que la representación contable evoluciona a la vez que los cambios en los arquetipos mentales de cada momento. Este trabajo se ha centrado en el cambio de mentalidad que se dio con el paso de la Edad Media al Renacimiento, sin embargo, este cambio también se puede extrapolar a otros momentos históricos como, por ejemplo, al de la irrupción de la Ilustración durante el siglo XVIII (Carmona et al., 2004) o al del Posestructuralismo el en siglo XX (Macintosh 2013). Además, entendemos, que este cambio también se dará en el siglo XXI como consecuencia del surgimiento de nuevas ideas como, por ejemplo, las del nuevo papel de la mujer en la sociedad o las del cambio climático.

\section{Financiación}

Esta investigación no recibió ninguna subvención específica de organismos de financiación de los sectores público, comercial o sin ánimo de lucro.

\section{Conflicto de intereses}

Los autores declaran no tener ningún conflicto de intereses. 


\section{Referencias}

Aho, J. (2005). Confession and Bookkeeping. The Religious, Moral and Rhetorical Roots of the Modern Accounting. Albany: State University of Ney York Press.

Almenar Fernández, L., Chismol Muñoz-Caravaca, G., \& Ruiz Domingo, Ll. (2017). Aproximación a la desigualdad económica a través de fuentes fiscales bajomedievales: Valls (1378), Sevilla (1384) y Palma (1478). El Futuro del Pasado, 8, 55-82. http://dx.doi.org/10.14516/fdp.2016.008. 001.002

Alonso González, J. C. (2004). La psicología analítica de Jung y sus aportes a la psicoterapia. Universitas Psychologica, 3(1), 55-70.

Álvarez-Dardet, C., \& Capelo Bernal, M. (2003). Contractual relationships and accounting change: the case of Agüera Wholesalers, 1770-1835. Accounting History, 8(1), 61-88. https://doi.org/10.1177/103237320300800104

Aquino, S. T. de. (1265-1274). Suma de Teología (Cuarta Edición; J. Martorell \& G. Celada, Trads. 2001). Madrid: Biblioteca de Autores Cristianos.

Baxter, W. T. (1980). The Account charge and discharge. The Accounting Historians Journal, 7(1), 69-71.

Bennassar, B., \& Jacquart, J. (2005). Historia moderna $\left(5^{\mathrm{a}}\right.$ edición). Madrid: Ediciones Akal, S.A.

Bhimani, A. (1994). Accounting enlightenment in the age of reason. European Accounting Review, 3(3), 399-442. https: //doi.org/10.1080/09638189400000030

Bryer, R. A. (2000a). The history of accounting and the transition to capitalism in England. Part one: theory. Accounting, Organizations and Society, 25(2), 131-162. https://doi.org/10.1016/S0361-3682(99)00032-X

Bryer, R. A. (2000b). The history of accounting and the transition to capitalism in England. Part two: evidence. Accounting, Organizations and Society, 25(4), 327-381. https://doi.org/10.1016/S0361-3682(99)00033-1

Bryer, R. A. (2006). The genesis of the capitalist farmer: Towards a Marxist accounting history of the origins of the English agricultural revolution. Critical Perspectives on Accounting, 17(4), 367-397. https://doi.org/10.1016/j.cpa. 2004.04.007

Burns, W.E (2001). The Scientific Revolution: An Encyclopedia. Santa Barbara (California): ABC-CLIO.

Busch, T. (1997). Management, accounting and cognition. Scandinavian Journal of Management, 13(1), 39-49. https: //doi.org/10.1016/S0956-5221(96)00029-2

Carley, A. (1894). The Principles of Book-keeping by Double Entry. Cambridge: Cambridge University.

Carmona Moreno, S., \& Ezzamel, M. (2006). Accounting and religion a historical perspective. Accounting History, 11(2), 117-127. https://doi.org/10.1177/ 1032373206063109

Carmona Moreno, S., Ezzamel, M., \& Gutiérrez Hidalgo, F. (2004). Accounting History Research: Traditional and Accounting History Perspectives. De Computis: Revista Española de Historia de La Contabilidad, 1, 24-53.

Carruthers, B. G., \& Espeland, W. N. (1991). Accounting for Rationality: Double-Entry Bookeeping and the Retoric of Economic Rationality. Accounting Journal of Sociology, 97(1), 31-69.

Castillo, D. del (1522). Tratado de Cuentas en el qual se contienen que coas es cuenta y a quien y como han de dar cuenta los tutores y otros administradores de bienes agenos $\left(1^{\mathrm{a}}\right)$. Burgos: Alonso de Melgar.

Chan, A. (2017). Accounting Systems in Cultural Context: A Research Framework for China Studies in Global Eco- nomy. Journal of Modern Accounting and Auditing, 3(2), 45-50.

Chaplygina, I., \& Lapidus, A. (2016). Economic thought in scholasticism. En G. Faccarello \& H. D. Kurz (Eds.), Handbook on the History of Economic Analysis: v. II (pp. 20-42). Northampton (MA), USA: Edward Elgar Publishing.

Cordery, C. (2015). Accounting history and religion: A review of studies and a research agenda. Accounting History, 20(4), 430-463. https://doi.org/10.1177/ 1032373215610590

De Roover, R. (1983). Economía Escolástica. Estudios Públi$\cos , 9,89-121$.

Derks, H. (2008). Religion, capitalism and the rise of doubleentry bookkeeping. Accounting, Business and Financial History, 18(2), 187-213. https://doi.org/10.1080/ 09585200802058735

Dobie, A (2015). Accounting at Durham Cathedral Priory. Management and Control of a Major Ecclesiastical Corporation, 1083-1539 (Palgrave Studies in the History of Finance). London: Palgrave Macmillan.

Edwards, J.R. (1989). A History of Financial Accounting. London: Routledge.

Englard, I. (2009). Corrective and Distributive Justice: From Aristotle to Modern Times. Oxford: Oxford University Press.

Ellerman, D. P. (1985). The Mathematics of Double Entry Bookkeeping. Mathematics Magazine, 58(4), 226-233.

Galbraith, J. K. (1989). Historia de la Economía, Barcelona: Ariel.

Gordley, J. (2013). Los fundamentos morales del derecho privado. Ius et Veritas, 23(47), 16-34.

Gother, J. (1685). A Papist misrepresented, and represented. Or, A two-fold character of Popery. London: Challoner, Richar.

Granada, F. L. de (1559). Libro de la oración y meditación (edición de 1994). Madrid: Fundación Universitaria Española.

Grendler, P.F. (2002). The Universities of the Italian Renaissance. Baltimore, MD: The Johns Hopkins University Press.

Heeffer, A. (2011). On the curious historical coincidence of algebra and double-entry bookkeeping. In K. François, B. Löwe, T. Müller, \& V. K. Bart (Eds.), Foundations of the formal sciences VII : bringing together philosophy and sociology of science, 32, 109-130. London, UK: College Publications.

Hernández Esteve, E. (2005). Reflexiones sobre la naturaleza y los orígenes de la contabilidad por partida doble. Pecunia: Revista de La Facultad de Ciencias Económicas y Empresariales, 1, 93-124.

Hernández Esteve, E. (2017). El Magisterio de Luca Pacioli a los 500 Años de su Muerte: Toma de Conciencia de su Papel como Abanderado del Renacimiento Comercial y Económico. De Computis - Revista española de historia de la contabilidad, 14(27), 6-29. http://dx.doi.org/10.26784/ issn.1886-1881.v14i27.312

Hopwood, A. G. (1987). The archaeology of accounting systems. Accounting, Organizations and Society, 12(3), 207234. https://doi.org/10.1016/0361-3682(87)90038-9

Hopwood, A. G. (1990). Accounting and Organisation Change. Accounting Auditing and Accountability Journal, 3(1), 7-17. https://doi.org/10.1108/09513579010145073

Hopwood, A. G. (1992). Accounting calculation and the shifting sphere of the economic. European Accounting Review, 1(1), 125-142. https://doi.org/10.1080/ 09638189200000007

Hopwood, A.G., \& Miller, P. (1994). Accounting as social and 
institutional practice. Cambridge, UK: Cambridge University Press.

Hoskin, K., \& Macve, R. (1986). Accounting and the examination: a genealogy of disciplinary power. Accounting Organizations and Society, 11(2), 105-136.

Jensen, M. C., \& Meckling, W. H. (1976). Theory of the Firm: Managerial Behaviour, Agency Costs and Ownership Structure. Journal of Financial Economics, 3(4), 305360.

Jones, R. (1985), Accounting in English local government: from the Middle Ages to c. 1835, Accounting and Business Research, 15(59), 197-210.

Jung, C. G. (1969). Collected Works of C.G. Jung, Psychology and Religion: West and East (v. 11). Princeton, USA: Princeton University Press.

Laughlin, R. (1987). Accounting systems in organizational contexts: A case for critical theory. Accounting, Organizations and Society, 12(5), 479-502. https://doi.org/10. 1016/0361-3682(87)90032-8

Laughlin, R. (1988). Accounting in its social context: An analysis of the accounting systems of the Church of England. Accounting, Auditing and Accountability Journal, 1(2), 19-42. https://doi.org/10.1108/EUM0000000004622

Lemarchand, Y. (1994). Double entry versus charge and discharge accounting in eighteenth-century France. Accounting Business and Financial History, 4(1), 119-145. https: //doi.org/10.1080/09585209400000040

León, F. L. de (1527-1591). Exposición del Libro de Job. Madrid: M. Rivadeneyra, 1855.

López Pérez, M. V. (1999). Captación e interpretación en Contabilidad. Tesis Doctoral. Granada: Universidad de Granada.

López Pérez, M. V., \& Rodríguez Ariza, L. (2002). Aplicación del enfoque cognitivo a la metodología contable. Revista Española de Financiación y Contabilidad, 31(112), 461494.

López Pérez, M. V., \& Rodríguez Ariza, L. (2003). Un caso de interdisciplinariedad en teoría de la contabilidad: los cambios contables desde el enfoque cognitivo-lingüístico. Encuentros Multidisciplinares, 15(5), 62-78.

Macintosh, N. (2013). Accounting, Accountants and Accountability. London, UK: Routledge.

Macve, R.H. (1996). Pacioli's Legacy. In T.A. Lee, R. Bishop and R.H. Parker (eds) Accounting History from the Renaissance to the present (pp. 3-30). New York: Garland.

Martínez Martínez, (2010). Ecos cronísticos del Rey-Juez medieval. Cuadernos de Historia del Derecho, vol. extraordinario, 303-356.

McCarthy, P., Sangster, A., \& Stoner, G. (2008). Pacioli and humanism: pitching the text in Summa Arithmetica. Accounting History, 3(2), 183-206. https://doi.org/10.1177/ 1032373207088178

Miller, P. (1991). Accounting innovation beyond the enterprise: Problematizing investment decisions and programming economic growth in the U.K. in the 1960s. Accounting, Organizations and Society, 16(8), 733-762. https: //doi.org/10.1016/0361-3682(91)90022-7

Miller, P., \& O'Leary, T. (1987). Accounting and the construction of the governable person. Accounting, Organizations and Society, 12(3), 235-265. https://doi.org/10.1016/ 0361-3682(87)90039-0

Miller, P., \& O'Leary, T. (1989). Hierarchies and American Ideals, 1900-1940. The Academy of Management Review, 14(2), 250-265. https://doi.org/10.5465/amr.

\subsection{4}

Moro, T. (1516). Utopía. Madrid: Ed. Taurus, 2012.

Napier, C. J. (2006). Accounts of change: 30 years of historical accounting research. Accounting, Organizations and Society, 31, 445-507. https://doi.org/10.1016/j.aos. 2005.12.004

Nobes, C. W., \& Zaid, O. A. (2001). Were Islamic records precursors to accounting books based on the Italian method? A comment [with Response]. The Accounting Historians Journal, 28(2), 207-218. http://www.jstor.org/ stable/40698527

Noke, C. (1981). Accounting for Bailiffship in Thirteenth Century England. Accounting and Business Research, 11(42), 137-151. https://doi.org/10.1080/00014788. 1981.9729691

Oldroyd, D., \& Dobie, A. (2009). Bookkeeping. In J. R. Edwards \& S. P. Walker (Eds.), The Routledge Companion to Accounting History (pp. 95-119). New York, USA: Routledge.

Pacioli, L. (1494). Summa de Arithmetica, Geometria, Proportioni et Proportionalita, Venice: Paganino de' Paganini.

Pacioli, L. (1509). De Divina Proportione Facsimile (in Black and White) of the Original Version of 1509. Leopold Publishing.

Plazaola Artola, J. (2015). Modelos y teorías de la historia del arte, $4^{\mathrm{a}}$ ed. Universidad de Deusto.

Previts, G. J., \& Bricker, R. (1994). Fact and Theory in Accounting History: Presentmindedness and Capital Market Research. Contemporary Accounting Research, 10(2), 625-641. https://doi.org/10.1111/j.1911-3846. 1994.tb00408.x

Rodriguez de Monforte, P. (1584). Sueños misteriosos de la escritura, en discvrsos sagrados, políticos y morales con un elenco de sermones para las dominicas de adviento. Biblioteca de Castilla-La Mancha: Fondo Antiguo.

Rojas González, R. (2019). El lenguaje de las matemáticas: Historias de sus símbolos. Ciudad de México: Fondo de Cultura Económica.

Ruiz Gallegos, J. (2010). La justicia del más allá a finales de la Edad Media a través de fuentes iconográficas. El ejemplo de la diócesis de Calahorra y La Calzada. Clio \& Crimen, 7, 238-242.

Rummel, E. (2009). The Renaissance Humanists. En A. J. Hauser y D. F. Watson (Eds.), A History of Biblical Interpretation, v. 2: The Medieval Though the Reformation Periods (v. 2, pp. 292-310). Cambridge: William. B. Eerdmans Publishing Company.

Salvador de Solórzano, B. (1590). Libro de Caxa y Manual de cuentas de Mercaderes, y otras personas, con declaración dellos (Facsímil). Madrid: Instituto de Contabilidad y Auditoría de Cuentas, Ministerio de Economía y Hacienda.

Sánchez, P. (1584). De la cuenta estrecha que a de dar el que recibe mucho. Árbol de consideración y varia doctrina. Biblioteca de Castilla-La Mancha (España): Fondo Antiguo, 4-8661, 32r-32v.

Sangster, A., Stoner, G. N., \& McCarthy, P. (2008). The market for Luca Pacioli's Summa Arithmetica. The Accounting Historians Journal, 35(1), 111-134. http: / / www.jstor. org/stable/40698369

Sangster, A. (2016). The Genesis of Double Entry Bookkeeping. The Accounting Review, 91(1), 299-315. https://doi. org/10.2308/accr-51115

Sangster, A. (2018). Pacioli's Lens: God, Humanism, Euclid, and the Rhetoric of Double Entry. The Accounting Review, 93(2), 299-314. https://doi.org/10.2308/accr-51850

Sangster, A., \& Rossi, F. (2018). Benedetto Cotrugli on dou- 
ble entry Bookkeeping. De Computis - Revista española de historia de la contabilidad, 15(2), 22-38. https://doi.org/ 10.26784/issn.1886-1881.v15i2.332

Schumpeter, J. A. (1934). The Theory of Economic Development. An Inquiry into Profits, Capital, Credit, Interest and the Business Cycle. Cambridge: Harvard University Press.

Scorgie, M. E. (1989). "The Role of Negative Numbers in the Development of Double Entry Bookkeeping": A Comment. Journal of Accounting Research, 27(2), 316-318. https: //doi.org/10.2307/2491239

Sombart, W. (1902). Der moderne Kapitalismus: historischsystematische Darstellung des gesamteuropäischen Wirtschaftslebens von seinen Anfängen bis zur Gegenwart. Bd. 3, Das Wirtschaftsleben im Zeitalter des Hochkapitalismus - Halbbd. 2, Der Hergang der hochkapitalistischen Wirtschaft; Die Gesamtwirtschaft. Munich: Duncker y Humblot.

Sombart, W. (1930). The Quintessence of Capitalism: A Study of the History and Psychology of the Modern Business Man. London: Routledge Thoemmes Press.

Sombart, W. (1953). Medieval and modern commercial enterprise. In F. C. Lane (Ed.), Enterprise and secular change: readings in economic history. Illinois: Homewood, Irwin.

Stevens, A. (1994). Jung o la búsqueda de la identidad. Madrid: Editorial Debate.

Thompson, G. (1991). Is accounting rhetorical? Methodology, Luca Pacioli and printing, Accounting, Organizations and Society, 16 (5/6), 572-99. https://doi.org/10.1016/ 0361-3682(91)90042-D

Toms, S. (2010). Calculating profit: A historical perspective on the development of capitalism. Accounting Organizations and Society, 35(2), 202-221. http://dx.doi.org/10. 1016/j.aos.2009.06.002

Trevor-Roper, H. (1965). The rise of Christian Europe. London: Thames \& Hudson).

Trifilio, S. (2018). The Economic Theory of the Scholastics as a Contractual Analysis. Journal des Économistes et des Études Humaines, 24(1), 1-6. https://doi.org/10.1515/ jeeh-2018-0005

Ussher, J. (1645). A body of Divinitie: Or the summe and substance of Christian Religion, catechistically prounded, and explained, by way of question and answer. London: M.F. for Downes and Geo Badger.

Vilar, P. (1982). Oro y moneda en la Historia. Barcelona: Ariel.

Villaluenga de Gracia, S. (2013). Aproximación a los fundamentos contables, legales y morales del método de cargo y descargo por el que se rendían cuentas. De Computis: Revista española de historia de la contabilidad, 19, 76-93. http://doi.org/10.26784/issn.1886-1881.v10i19.57

Villaluenga de Gracia, S., \& Llibrer Escrig, I. (2019). El cargo y descargo como procedimiento jurídico-contable neutralizador de los desequilibrios derivados de las relaciones de agencia". Revista de Contabilidad-Spanish Accounting Review, 22 (2), 225-232. http://doi.org/10.6018/rcsar. 382281

Vlaemminck, J. H. (1961). Historia y doctrina de la contabilidad. Madrid: Ejes.

VVAA (1987). The Metropolitan Museum of Art: The Renaissance in Italy and Spain. New York: The Metropolitan Museum of Art.

Weber, M. (1927). General Economic History. Trans. y F.H.Knight. London: Allen \& Unwin.

Weber, M. (1956). Economía y Sociedad (2 ${ }^{\mathrm{a}}$ edición en español de 2002; J. Medina Echavarria, Trans.). Madrid: Fondo de Cultura Económica de España, SL.

Yamey, B.S. (1994). Luca Pacioli, the Summa and De Scriptus. In A. Gebsattel \& B. S. Yamey (Eds.), Luca Pacioli: Exposi- tion of Double Entry Bookkeeping, Venice, 1494 (pp. 1133). Venice: Albrizzi Editore.

Zaid, O. A. (2000). Were Islamic records precursors to accounting books based on the ITALIAN Method? The Accounting Historians Journal, 27(1), 73-90. http://www. jstor.org/stable/40698486

Zamora, Fray Juan de (1799): "Sobre los usos en que los Eclesiásticos deben invertir el sobrante de su renta”, Eclesiástico perfecto, tercera impresión, Madrid. 